\title{
Malignant Ovarian Cyst
}

National Cancer Institute

\section{Source}

National Cancer Institute. Malignant Ovarian Cyst. NCI Thesaurus. Code C3843.

A cystic cancerous tumor arising from the ovary. 